\title{
Analysis on the Problem of Music Copyright in Network Broadcast
}

\author{
XIN YUE* \\ Law school \\ China Jiliang University \\ Hangzhou, China
}

\begin{abstract}
The vigorous development of network broadcast brings economic benefits as well as some negative effects. The purpose of this paper is to judge that the unauthorized use of music by network anchors infringes the right of communication through information network and performing rights of copyright owners and falls into the scope of fair use and analyze the difficulties of copyright owners in safeguarding their rights and making claims in the field of webcast, and put forward some suggestions for strengthening copyright protection in the field of network broadcast, such as integrating relevant laws, clarifying infringement issues and enhancing copyright awareness.
\end{abstract}

\section{Keywords-Network Broadcast; Infringement; Music} Copyright

\section{INTRODUCTION}

In the era of network broadcast, with the growing prosperity of emerging markets, live streaming platforms are springing up like mushrooms. While it brings economic value to the society, it also leads to the rise of a new industry. At the same time, its negative effects are also appearing, such as the hysteresis of law. Law is the basis of a country's governance and the foundation of a country, which changes slowly and permanently. The emergence of new industries is obviously beyond the scope of explicit regulation by existing laws and today's webcast is one of them. While the content of network broadcast is rich, infringement problems arise due to improper use and performance of other people's published songs.

For example, on February 14, 2018, famous anchor Feng Timo played the song lover's heart for about 70 seconds during a live broadcast on the Douyu Live Streaming Platform owned by Douyu Company. When the song was played as background music, Feng Timo interacted with the users watching the live broadcast from time to time. After finishing the live broadcast, the whole broadcast was made into a video by the anchors and posted on the official platform of Douyu Live Broadcast. As long as the audience logs on the platform, they can watch and share it anytime and anywhere.

Since the lyricist Zhang Chao of the song lover's heart has signed the music copyright contract with Music Copyright Society of China, so Music Copyright Society of China can exercise the copyright in this song. Music Copyright Society of China sued Douyu Company, claiming that the company had directly infringed on its right to the dissemination of information on the Internet. It demanded Douyu Company to compensate for 30,000 yuan of copyright royalties, notary fees, attorney fees and other reasonable fees.

In the above cases, it is precisely because of the lack of clear regulation on the use of music copyright in network broadcast that copyright infringement disputes are triggered. This paper analyzes what kind of rights in the copyright law are violated by unauthorized use of music, whether it belongs to the category of fair use, and the obstacles that the rights holders face in appealing.

\section{INFRINGEMENT ANALYSIS OF MUSIC USE IN NETWORK BROADCAST}

Feng Timo played unauthorized songs in the live broadcast and recorded the video to be released on the platform, which caused a dispute between the recording artists' association and the platform. How to characterize the use of unauthorized music played by network anchors is worth thinking about.

\section{A. Whether Unauthorized Use of Music Falls Under the Category of Fair Use}

Article 22 of the copyright law provides that, in some cases, a work may be used without permission or payment of remuneration to the copyright owner, provided that the name of the author and the title of the work shall be specified and the other rights enjoyed by the copyright owner in accordance with this law shall not be infringed. It mainly includes several types: first, personal use or borrowing others' works to elaborate personal problems; second, the published works of individuals are used in the public domain; third, research or exhibitions for the purpose of improving educational standards. The collective is divided into 12 items.

The network anchor is involved in item 9: for the published works, the performance does not collect fees from the public or pay remuneration to the performers. There are two key points in this item. The first is the failure to collect fees from the public and the second is the failure to pay the performers. From the perspective of the live broadcast, the platform has a wide audience, and it can enter the platform to watch the live broadcast without paying necessary fees, which expands an entertainment platform for users. However, in fact, the platform indirectly collects rewards from users, converts virtual goods into real currency, and shares them with anchors according to a certain proportion, which has formed a wage chain relationship. 
In this way, the behavior of network anchor cannot be attributed to the category of reasonable use.

If the user does not give a reward, does it fall under the category of fair use? The answer is no, too. According to article 37 of China's Copyright Law, a performer (an actor or a performing entity) who exploits another person's work for a performance shall obtain permission from the copyright owner and pay the corresponding remuneration. When organizing a performance, the organizer shall obtain the license of the copyright owner and pay the corresponding remuneration. he exploitation for a performance of a work resulting from translation, adaptation, arrangement or annotation of a preexisting work shall be subject to the permission of the copyright owner of the translated, adapted, arranged or annotated work and the copyright owner of the original work, and shall pay corresponding remuneration.

The copyright owner's right to remuneration and the right to license the use of background music is based on the right of performance enjoyed by the copyright owner of a musical work When a song is played as background music during the business period of a commercial place, the operator usually believes that he has paid consideration when purchasing the music carrier, that is, he has paid the royalty to the copyright owner and no other fees are required. But in essence this consideration only includes the license fee for the individual user of the music work and the price of the music carrier. The operator may enjoy the performance at his own home free after purchase of charge just like ordinary consumers, but if he performs in a commercial place for commercial purposes, he shall obtain permission from and pay remuneration to the copyright owner.

Although the webcast platform is not a commercial place with offline and exclusive places as important elements in the common sense, its behavior meets the conditions of a commercial place, such as the use of background music, with their own live, so as to get a high reward. Therefore, it can be defined as an indirect commercial use without the permission of the copyright owner or payment of remuneration. So it still can't fall into the category of fair use.

\section{B. Whether Unauthorized Use of Music Infringes Upon Performance Rights}

According to article 10 item9 of the Copyright Law, the right of performance is the right to perform a work to the public and to publicly broadcast the work by various means .Performance includes mechanical performance and live performance. The performance of others' work shall be subject to the permission of the copyright owner. A free performance of a published work may take place without the permission of, or payment of remuneration to the copyright owner, provided that the name of the author and the title of the work shall be indicated and the other rights of the copyright owner shall not be infringed.

In network broadcast, the host plays music or performs music through the open network platform, which conforms to the element of public performance works. In essence, live streaming platforms and anchors are for profit rather than free performance. Therefore, if they only perform other people's works, they should obtain the permission of the copyright owner of the work in advance and pay a certain remuneration. However, if a work is to be adapted, translated or annotated, the permission of both the copyright owner and the copyright owner of the adapted work shall be obtained and corresponding remuneration shall be paid. At present, there are no corresponding restrictions on the use of music by anchors on live streaming platforms, and the awareness of copyright on live streaming platforms is not strong, resulting in a large number of infringement acts, but not stopped.

\section{Whether the Unauthorized Use of Music Violates the Right of Information Network Dissemination}

According to the article 10 item 12 of the Copyright Law, the right of information network dissemination is to provide works to the public through wired or wireless means, so that the public can obtain the right of works at a time and place selected by individuals

Whether a network anchor uses music in public without authorization infringes upon the rights of others should be discussed in two cases. First, it only discusses the process from the first broadcast to the next broadcast, leaving aside the fact that Feng Timo made the whole live broadcast into a video and posted it on the Internet in the above-mentioned cases. The law stipulates that the right of information network dissemination is to enable the public to choose whether to watch it at any time and any place. However, network broadcast is real-time, and the option of time period is controlled by the host rather than the audience. Therefore, from this point of view, the act does not comply with the provisions of article 10 of the copyright law. That is, the unauthorized use of music does not infringe the right of information network dissemination.

Secondly, if we include the act of anchor Feng Timo in the above case to judge whether the result is infringement by making videos and posting them on the Internet. The author believes that the retention and dissemination of video involves infringement. If the video is retained and released on the Internet, it belongs to the category of video works and conforms to the provisions of the law so that the public can obtain the works at any time and place selected by individuals, thus infringing the right of information network dissemination.

A similar ruling was made in a 2015 case involving the broadcast of a Chinese super league game, in which Sina.com sued Ifeng.com. The plaintiff claimed that the defendant provided simultaneous broadcasting of the event to the audience through the Internet without authorization, which violated the plaintiff's right of information transmission through the Internet. However, because the audience can not independently choose the viewing time, so the defendant's retransmission behavior is not of interactivity, so it does not constitute a violation of the right of information network transmission. In the end, the court did not decide that the act violated the right to spread information on the Internet. Instead, it decided that the act violated other rights that should be enjoyed by the copyright owner and unfair competition.

The dispute in both cases focuses on whether the right to disseminate information on the Internet has been violated. The controversial element is whether the public can watch it at a 
time and place chosen by individuals, that is, the difference between live broadcasting and retransmission and the retention of recorded video. The former is of interactivity and timeliness, while the latter is in accordance with the provisions of the law that the public is free to choose the time and place. According to the former, the right of information network dissemination does not belong to the right of infringement. So whether to judge infringement according to the specific details of the penalty.

\section{ObSTACLES TO THE APPEAL OF MUSIC COPYRIGHT IN LIVE STREAMING}

\section{A. It is Difficult for Copyright Owners to Protect Their Rights}

First of all, when a network anchor plays music or performs a song, there are different opinions about the nature of the gift. If it is defining as a reward, so it's a tort. But if it isn't including as a reward, it's a different story. Secondly, it is difficult to judge what rights the network anchor violates when singing. As a result, the period of right confirmation is long, the cost of infringement is low and the cost of safeguarding rights is high [1]. Thirdly, due to the large number of network anchors, it takes a lot of time to carefully review the personal live video, and it is also difficult to find out whether the reward behavior in the live broadcast is related to music playing or singing [2]. Therefore, the copyright owner's rights protection process becomes particularly difficult.

\section{B. It is Difficult for Copyright Owners to Claim Compensation}

When the establishment of the infringement, should the anchor or the platform to find a claim? The host and the platform agree that all the achievements of the host during the live broadcast shall be owned by the live streaming company with all intellectual property rights, ownership and relevant rights and interests. The all achievements herein naturally include the videos on the platform. According to the principle of consistency of rights and obligations, the live broadcasting company is the holder of these achievements and enjoys relevant rights and interests, so it shall naturally assume corresponding responsibilities for the legal consequences arising from the achievements.

So how should the amount of claim be calculated? Article 49 of the Copyright Law stipulates: where copyright or copyright-related rights are infringed, the infringer shall compensate the copyright owner according to his actual loss; Where the actual loss is difficult to calculate, compensation may be made on the basis of the illegal gains of the infringer. The amount of compensation shall also include the reasonable expenses paid by the right to stop the infringing act. But in the actual application of the law, it will be found difficult to enforce. Due to the large number of anchors in the company, it is difficult to directly determine the actual loss suffered by the infringer through the users' rewarding behavior. At the same time, the law is not clear about how to punish the infringement in network broadcast, and the popularity of the song will also become a factor affecting the compensation, so it is difficult to judge.

\section{SugGESTIONS ON STRENGTHENING COPYRIGHT PROTECTION IN THE FIELD OF NETWORK BROADCAST}

In recent years, the protection of music copyright in China has been gradually improved, and the copyright awareness in the music market has been greatly improved compared with before. However, with the emergence of the new model of network broadcast industry, the copyright issue still faces huge challenges. The copyright issue caused by the use of network broadcast to music is worth further study and discussion. Therefore, this paper puts forward several measures and suggestions to strengthen copyright protection in the field of network broadcast.

\section{A. Clarify the Infringement of Network Broadcast and Integrate Relevant Laws of Network Broadcast}

The traditional copyright law cannot completely solve the problems in the field of network broadcast. In the face of many legal blind spots arising from the development of science and technology, the way of identifying music copyright also needs to be improved with the emergence and development of new industries [3]. It is necessary to integrate a series of laws and regulations, such as Notice on Strengthening the Management of Online Performance, Notice on Strengthening the Management of Online Live Audio and Video Programs and Measures on the Management of Online Performance Business Activities, which have been issued in China to clarify the judgment of rights in the new field of online live broadcasting. For example, the copyright law (revised draft) submitted by the national copyright administration in 2017 proposed to replace existing the rights of showing and playing with broadcasting rights. The broadcasting rights is defined as the right to broadcast the work to the public through wireless or wired means or to rebroadcast the work, as well as the right to broadcast the work to the public through technical devices. In this way, the originally ill-defined means of transmission, such as webcast, can be regulated by the broadcasting rights, focusing on bringing the new field of network under the legal horizon [4].

\section{B. Increase Legislation Related to the Regulation of Platforms and Save Regulatory Costs}

In the face of such a huge host group, how to use the least time cost, with the most efficient way to review and supervise it? For this reason, there should be more explicit provisions in the legislation. For example, the multi-core supervision mode of administrative department supervision as kernel, platform mutual supervision and host and audience supervision as outer core can be adopted to supervise this field, so as to achieve the supervision goal in a short time. The supervision of network broadcast not only includes the content of network broadcast, but also should be included in the substantive review of the performance of rights and obligations of network broadcast platforms [5]. This measure can effectively remedy the loopholes that may appear in the process of relevant law enforcement. As a direct stakeholder in the abuse of power or non-performance of obligations of network broadcast platforms, timely reporting of problems on the platforms by network anchors and users is also the most direct and effective way. 


\section{Enhance the Copyright Awareness of Network Broadcast Platforms and Anchors}

As live broadcasting is still an emerging industry, there is little legal supervision in this field [6]. When anchors acquire network resources, they may easily neglect copyright issues. Through the popularity of infringement cases related to live streaming, it can serve as a warning to practitioners in the live streaming industry. At the same time, the platform can provide a learning platform for its anchors and encourage them to create. It can not only guarantee the originality of the works but also further avoid many unnecessary problems caused by infringement. On the other hand, the anchor should be trained in necessary knowledge related to copyright, so as to improve the awareness of copyright and reduce the occurrence of infringement [7].

\section{Clarify the Subject of Liability for Tort Compensation and Apply Punitive Damages}

Although the Copyright Law provides for the compensation of infringement damages, it is difficult to make a reasonable penalty due to the complicated situation and unclear regulation. In addition, the subject of the right in the penalty is unclear. There are different opinions about whether the anchor or the platform should assume the responsibility. This makes it very difficult for copyright owners to claim compensation. In view of this problem, according to the principle of consistent rights and obligations, the platform shall bear the tort liability for the infringing content in the video. However, when the compensation standard is not clear and the actual loss is difficult to calculate, punitive compensation can be taken for the infringement compensation in network broadcast, that is, the person liable bears a higher actual loss than the obligee. Then by raising the cost of violation to prevent and contain a large number of infringement acts and encourage the rights holders to carry out new creations, so that the infringer does not dare to infringement. By clarifying the liability of compensation, the author aims to promote the legality of copyright use in network broadcast, improve the applicability of copyright law in network broadcast, and practically solve the problem of compensation.

\section{E. Establish a Reasonable Authorization Model to Effectively Avoid the Infringement Risk}

From the current situation of the popularization of copyright awareness, it is obviously difficult to rely on the individual to maintain the copyright, especially the improper recording behavior is very likely to cause the infringement of the right to information network transmission. Therefore, the authorization model of copyright owner --live broadcast platform -- network anchor can be adopted [8]. The release of videos by anchors needs to be approved by the platform, and the use of music needs to be approved by the platform. The use of music copyright is also negotiated and purchased by the platform and the copyright owner. If the platform's behavior creates a risk, but it benefits from the maintenance of such a risk, then the platform should pay corresponding duty of care to others who may be violated by the risk, pay careful attention to the expansion of the risk range, and avoid infringing on the legitimate rights of others [9]. It's like this, layer upon layer of propelling, layer upon layer of regulation. On the one hand, if the infringement occurs, it is convenient to find the infringement supervisor to assume the corresponding responsibility, so as to provide a solution to the difficulty for copyright owners to protect their rights. On the other hand, in order to avoid the occurrence of infringement risks, regulators will consciously strengthen supervision, establish effective and effective ways of music copyright supervision and strictly control risks. For example, establish a music library only owned by the platform, upload the authorized music to the music library, and the anchors can only choose their own live music from the music library. To some extent, it plays a role in avoiding risks.

\section{CONCLUSION}

The unique entertainment and interactivity of network broadcast is gradually integrated into the life of the public and becomes the spice of people's life. However, the impact of network broadcast on the field of intellectual property rights has brought about many problems that cannot be ignored, especially the problem of copyright. In the process of using music, the infringement problem needs to be paid enough attention to by the platform and the anchor. How to make use of the new model to make the live broadcast industry bigger and better in the live broadcast era while avoiding a series of problems caused by infringement is worth our continuous exploration.

\section{REFERENCES}

[1] Li Yangfang: Network Broadcast, Short Video Music Legalization of the Road How to Go? In China Intellectual Property Rights Daily, May 3 , 2018.(In Chinese)

[2] See Li Hongli: Analysis of Music Copyright Infringement in Network Broadcast, In Legal Expo, no. 7, 2019, page 21. (In Chinese)

[3] See Yu Zhiqiang, An Examination and Future Construction of China's Internet Intellectual Property Crime Sanction System, Chinese Law, no. 3, 2014, pp. 163-164. (In Chinese)

[4] Zhao Shilan, Zhang Yingzi xuan, A Study on Music Copyright in Network Broadcast, In Music Communication, no.3, 2018, p. 105. (In Chinese)

[5] Guo Liangui: Copyright Protection of Short Video Content from the Perspective of Duty of Care, Electronic Intellectual Property Rights, no.10, 2016, page 92. (In Chinese)

[6] See Li Xiaoqing, A Study on Music Copyright in Network Broadcast, Legal Expo, no. 26, 2019, page 77. (In Chinese)

[7] Shi Yanming, Music Copyright Infringement Risk and Prevention Under the Economic Model of Network Broadcast, in Special Economic Zone issue 3, 2019, page 135. (In Chinese)

[8] See Si Si: On Digital Music Copyright Protection on Short Video Platforms, Journal of Southwest University of Political Science and Law, 5, 2018, p. 117. (In Chinese)

[9] See Xiong Jinguang, A Study on the Duty of Care for Safety in Tort Law, Law Press, 2007, p. 203. (In Chinese) 